\title{
Microwave Synthesis of a Nanoporous Hybrid Material, Chromium Trimesate
}

\author{
Sung Hwa Jhung, Jin-Ho Lee, and Jong-San Chang* \\ Research Center for Nanocatalysts, Korea Research Institute of Chemical Technology, P.O. Box, 107, Yusung, \\ Daejeon 305-600, Korea. "E-mail: jschang@krict.re.kr \\ Received December 30, 2004
}

Key Words : Microwave synthesis, Nanoporous hybrid material, Chromium trimesate, MIL-100

Recently, the domain of nanoporous materials has been enlarged very much to the development of porous hybrid materials designated as metal-organic frameworks (MOF), ${ }_{1}$ porous coordination polymers ${ }^{2}$ or organic-inorganic hybrids $\mathrm{s}^{3,4}$ which are the most recently highlighted class of materials consisting of metal ions linked together by organic bridging ligands in the framework. The attraction of combining properties from both inorganic and organic components has led to a quest of research toward new hybrid materials with potential applications including gas storage, catalysis, separation, and molecular recognition..$^{1-4}$ Very recently, Férey and co-workers have reported a novel hybrid material, chromium trimesate (designated as MIL-100), which has a hierarchical pore system (micro: 5-9 Aं; mesoporous: 25-30 $\AA$ ) with a very high Langmuir surface area. ${ }^{5}$

Syntheses of the porous hybrid materials have been carried out mainly by hydrothermal or solvothermal synthesis generally in a period of several days. Microwave techniques have attracted growing attention for the rapid synthesis of nanoporous materials requiring several days to prepare under hydrothermal conditions. ${ }^{6}$ Potential advantages of this technique in the synthesis of porous materials include phase selectivity, ${ }^{7}$ narrow particle size distribution ${ }^{8}$ and facile morphology control ${ }^{9}$ besides fast crystallization. ${ }^{6}$

However, microwave technique has not been applied to the synthesis of nanoporous hybrid materials yet even though the microwave syntheses of not only organic molecules but also inorganic materials have been often studied. ${ }^{10}$ In this communication, we report the first successful result on the microwave synthesis of porous chromium trimesate as an organic-inorganic hybrid material.

The porous chromium trimesate (MIL-100) was synthesized in aqueous media similar to the previous reported method $^{5}$ except using microwave irradiation ${ }^{11}$ as a heating source. The molar composition of reactant mixture was 1.0 Cr: $0.67 \mathrm{H}_{3} \mathrm{BTC}$ (benzene tricarboxylic acid): $2.0 \mathrm{HF}: 290$ $\mathrm{H}_{2} \mathrm{O}$. The reactant mixture was loaded in a Teflon autoclave, which was sealed and placed in a microwave oven (Mars-5, CEM). The autoclave was heated to the reaction temperature of $220{ }^{\circ} \mathrm{C}$ and kept for a predetermined time. The structure and crystallinity of the synthesized samples were determined by X-ray powder diffraction. The TGA pattern was obtained with a thermal analyzer in the air flow. The sorption experiments were carried out volumetrically.

Figure 1 shows the XRD patterns of as-synthesized chromium trimesate obtained by varying crystallization time at $220{ }^{\circ} \mathrm{C}$ under microwave irradiation. The XRD patterns of the samples obtained from microwave irradiation are well consistent with the pattern ${ }^{5}$ of MIL-100 synthesized for 4 days at $220{ }^{\circ} \mathrm{C}$ using conventional hydrothermal heating. However, the chromium trimesate materials synthesized using microwave method contained unreacted metallic chromium species until $2 \mathrm{~h}$ of crystallization. The crystal yield of the chromium trimesate based on chromium from microwave synthesis for $4 \mathrm{~h}$ is $44 \%$, which is comparable with the result of $45 \%$ in the conventional synthesis for 4 days. 5

The TGA profile of Figure 2 reveals a stability of the title compound up to $270{ }^{\circ} \mathrm{C}$. The thermal stability determined with TGA are very similar to the previous results. ${ }^{5}$ The chromium trimesate synthesized by microwave heating shows nitrogen adsorption-desorption isotherm very similar to the isotherm of MIL-100 (Data not shown), ${ }^{5}$ representing the permanent porosity and similarity of the pore structure of the hybrid materials synthesized by both methods. For multiplayer coverage of $\mathrm{N}_{2}$, we estimate the apparent BET surface area and pore volume to be $1700 \mathrm{~m}^{2} / \mathrm{g}$ and 0.97 $\mathrm{mL} / \mathrm{g}$, respectively. From $\mathrm{H}_{2}$ adsorption isotherm (Figure 3 ), the adsorption capacity of hydrogen at $-196{ }^{\circ} \mathrm{C}$ and $1 \mathrm{~atm}$ is estimated to be about $150 \mathrm{~mL} / \mathrm{g}$ (STP), which is comparable with the results adsorbed on various MOFs and porous hybrid materials. ${ }^{12}$ The re-adsorption isotherm after the desorption at $-196{ }^{\circ} \mathrm{C}$ of the pre-adsorbed hydrogen is same as the adsorption isotherm on the fresh sample, representing that there is no chemisorption site in the chromium trimesate

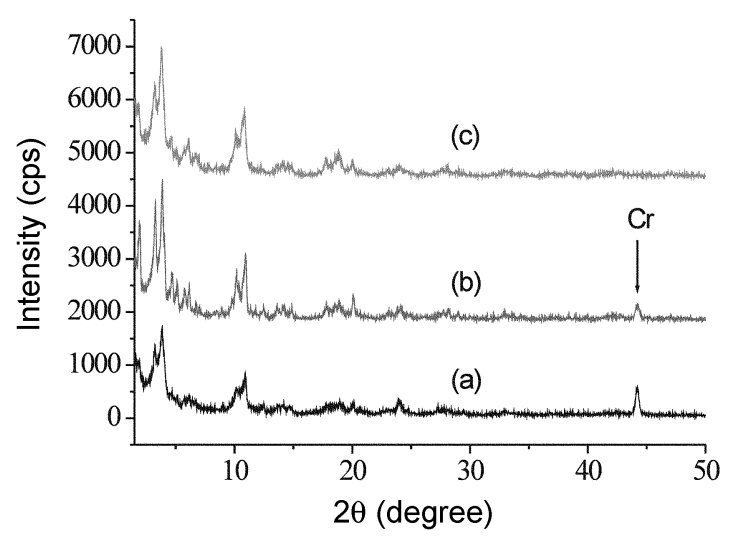

Figure 1. XRD patterns of as-synthesized chromium trimesate (MIL-100) synthesized by microwave method in various crystallization times: (a) $1 \mathrm{~h}$, (b) $2 \mathrm{~h}$, and (c) $4 \mathrm{~h}$ at $220^{\circ} \mathrm{C}$. The unreacted metallic chromium is shown in (a) and (b). 


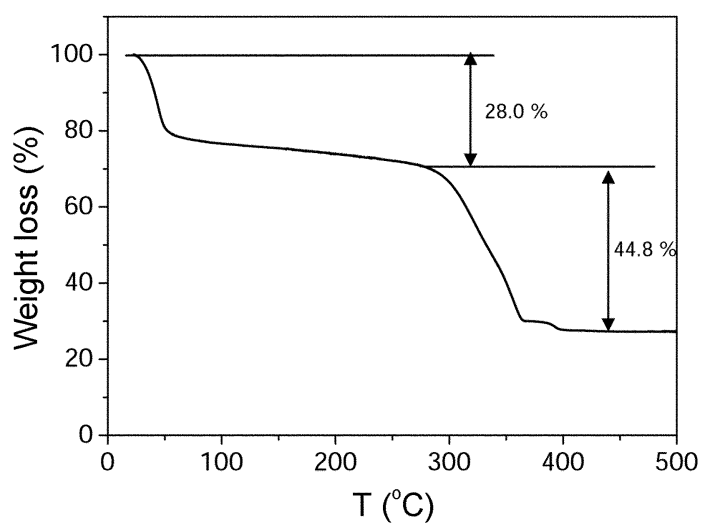

Figure 2. TGA pattern of MIL-100 synthesized for $4 \mathrm{~h}$ at $220{ }^{\circ} \mathrm{C}$ by microwave method. The heating rate was $2{ }^{\circ} \mathrm{C} / \mathrm{min}$ under the flow of air $(100 \mathrm{~mL} / \mathrm{min})$ and the sample weight was about $10 \mathrm{mg}$.

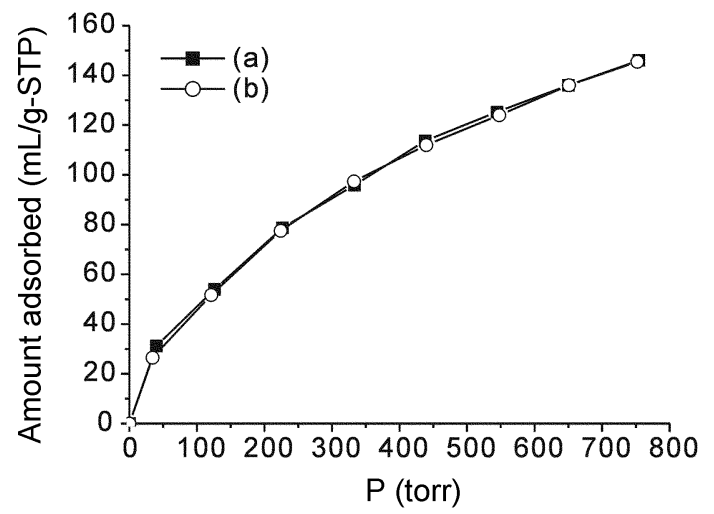

Figure 3. Adsorption isotherms of hydrogen over the chromium trimesate at $-196{ }^{\circ} \mathrm{C}$. The isotherms are consisted of (a) the adsorption isotherm on the fresh sample and (b) the re-adsorption isotherm after evacuation of the hydrogen-adsorbed sample at -196 ${ }^{\circ} \mathrm{C}$.

similar to ordinary MOFs. ${ }^{12}$ These adsorption results indicate that the title compound is highly porous after dehydration, so that it takes up gases very readily.

For the porous chromium trimesate, microwave technique provides the faster synthesis about 20 times compared with the conventional way. Although the formation of porous hybrids under hydrothermal conditions are not well established yet, the faster synthesis of chromium trimesate under microwave irradiation appears to be accomplished through the combination of fast dissolution of the precursors, especially metallic chromium and acceleration of the condensation of the oxygen-metal networks. Considering the limited solubility of precursors in acidic condition, it is necessary to quickly dissolve precursors for the faster synthesis of the title compound. Microwave irradiation is believed to give rise to the fast dissolution of less soluble metal and organic precursors through selective heating of microwave active species, leading to suppression of an induction period. For organic-inorganic hybrid compounds, it is known that carboxylic anions are multidentate and the organic moiety acts as a template during the condensation of the oxygen-metal networks when synthesized under hydrothermal conditions. ${ }^{3}$ The condensation step is believed to be greatly accelerated with the superheating effect ${ }^{6,13}$ of microwaves, resulting in the shortening of the overall synthesis time.

In summary, we have first shown that an organic-inorganic hybrid material, chromium trimesate, is synthesized efficiently within several hours and its physicochemical and textural properties are very similar to those synthesized by conventional hydrothermal heating. This work provides a good opportunity to expand the application of microwave technique to the synthesis of porous hybrid materials from syntheses of both organic and inorganic materials.

Acknowledgements. This work was supported by KRICT and MOCIE. The authors thank Professor G. Férey and Dr. C. Serre for beneficial discussion.

\section{References}

1. (a) Yaghi, O. M.; O'Keeffe, M.; Ockwig, N. W.; Chae, H. K.; Eddaoudi, M.; Kim, J. Nature 2003, 423, 705. (b) James, S. L. Chem. Soc. Rev. 2003, 32, 276.

2. Kitagawa, S.; Kitaura, R.; Noro, S.-I. Angew. Chem. Intl. Ed. 2004, 43, 2334

3. Férey, G. Chem. Mater. 2001, 13, 3084.

4. Férey, G.; Mellot-Draznieks, C.; Serre, C.; Millange, F. Acc. Chem. Res. 2005, 38, 217.

5. Férey, G.; Serre, C.; Mellot-Draznieks, C.; Millange, F.; Surblé, S.; Dutour, J.; Margiolaki, I. Angew. Chem. Intl. Ed. 2004, 43, 6296.

6. Park, S.-E.; Chang, J.-S.; Hwang, Y. K.; Kim, D. S.; Jhung, S. H.; Hwang, J.-S. Catal. Survey Asia 2004, 8, 91.

7. (a) Jhung, S. H.; Chang, J.-S.; Hwang, J. S.; Park, S.-E. Micropor. Mesopor. Mater. 2003, 64, 33; (b) Jhung, S. H.; Lee, J.-H.; Yoon, J. W.; Hwang, J.-S.; Park, S.-E.; Chang, J.-S. Micropor. Mesopor. Mater. 2005, 80, 147

8. Kang, K.-K.; Park, C.-H.; Ahn, W.-S. Catal. Lett. 1999, 59, 45.

9. (a) Jhung, S. H.; Chang, J.-S.; Hwang, Y. K.; Park, S.-E. J. Mater. Chem. 2004, 14, 280; (b) Hwang, Y. K.; Chang, J.-S.; Park, S.-E.; Kim, D. S.; Kwon, Y.-U.; Jhung, S. H.; Hwang, J.-S.; Park, M.-S. Angew. Chem. Intl. Ed. 2005, 44, 557.

10. (a) Rao, K. J.; Vaidhyanathan, B.; Ganguli, M.; Ramakrishnan, P. A. Chem. Mater. 1999, 11, 882; (b) Larhed, M.; Moberg, C.; Hallberg, A. Acc. Chem. Res. 2002, 35, 717.

11. (a) Yoon, J. W.; Jhung, S. H.; Kim, Y. H.; Park, S.-E.; Chang, J.-S. Bull. Korean Chem. Soc. 2005, 26, 558; (b) Jhung, S. H.; Chang, J.-S.; Hwang, Y. K.; Grenéche, J.-M.; Férey, G.; Cheetham, A. K. J. Phys. Chem. B 2005, 109, 845.

12. (a) Rowsell, J. L. C.; Millward, A. R.; Park, K. S.; Yaghi, O. M. J. Am. Chem. Soc. 2004, 126, 5666; (b) Dybtsev, D. N.; Chun, H.; Kim, K. Angew. Chem. Intl. Ed. 2004, 43, 5033; (c) Lee, E. Y; Suh, M. P. Angew. Chem. Intl. Ed. 2004, 43, 2798.

13. Conner, W. C.; Tompsett, G.; Lee, K.-H.; Yngvesson, K. S. J. Phys. Chem. B 2004, 108, 13913. 